Artículo de Revisión

\title{
Odontología para bebés: una posibilidad práctica de promoción de salud bucal
}

Marina Moscardini Vilela ${ }^{1}$;

Stephanie Díaz Huamán ${ }^{1}$;

Moara De Rossi ${ }^{1}$;

Paulo Nelson-Filho ${ }^{2}$;

Andiara De Rossi ${ }^{3}$

\section{Resumen}

Objetivo. Revisar la literatura sobre la filosofía en Odontología para Bebés. Síntesis de datos. A pesar de que la promoción de la salud es muy practicada en todas las áreas de la salud, la odontología se caracteriza por restar importancia a la prevención de enfermedades bucales y a los tratamientos preventivos, cuando estos son realizados, ya los dientes deciduos se encuentran altamente comprometidos por la caries dental. Los resultados alcanzados a través de la enseñanza de tratamiento odontológico a bebés, en diferen- tes partes del mundo, tienen un futuro promisorio, ya que enfatiza las particularidades de su crecimiento y desarrollo infantil, considera al bebé como un todo, y no solamente desde el punto de vista de salud bucal. Conclusiones. La buena práctica de la odontología para bebés brinda la posibilidad de fomentar la salud y prevenir la enfermedad, de una forma muy simple, eficaz y de bajo costo.

Palabras clave: promoción de la salud, odontología preventiva, odontología para bebés, educación en salud bucal.

Artigo de Revisão

\section{Odontologia para bebês: uma possibilidade prática de promoção de saúde bucal}

\section{Resumo}

Objetivo: Revisar a literatura sobre a filosofia da Odontologia para Bebês. Síntese dos dados: Embora a promoção e a manutenção de saúde sejam muito preconizadas atualmente em todas as áre- as da saúde, a Odontologia tem se caracterizado por uma prática que pouco privilegia a prevenção da ocorrência das doenças e as ações preventivas e quando são empregadas, ocorrem tardiamente, quase sempre quando a dentição decídua já se encontra em grande parte comprometida pela cárie

${ }^{1}$ Post grado, Departamento de Clínica Infantil de la Facultad de Odontología de la Universidad de São Paulo - Ribeirão Preto (FORP-USP), Ribeirão Preto, SP, Brasil.

${ }^{2}$ Profesor Titular, Departamento de Clínica Infantil de la Facultad de Odontología de la Universidad de São Paulo - Ribeirão Preto (FORP-USP), Ribeirão Preto, SP, Brasil.

${ }^{3}$ Profesora Asociada, Departamento de Clínica Infantil de la Facultad de Odontología de la Universidad de São Paulo - Ribeirão Preto (FORP-USP) Ribeirão Preto, SP, Brasil. 
dentária. Os resultados alcançados através da Odontologia para Bebês, em diversas partes do mundo, têm apontado para um futuro promissor, que enfatiza as particularidades do crescimento e desenvolvimento infantis e considera o bebê como um todo, e não apenas do ponto de vista de saúde bucal. Conclusões:
Uma boa prática odontológica para bebês possibilita promover a saúde e prevenir a doença de uma forma simples, eficaz e de baixo custo.

Palavras-chave: promoção da saúde, odontologia preventiva, odontologia para bebês, educação em saúde bucal

\section{Review Article}

\section{Dentistry for babies: a practical possibility of oral health promotion}

\begin{abstract}
Objective: To review the literature concerning the philosophy of Dentistry for Babies.

Data synthesis: Although the promotion and maintenance of health have been very recommended currently in all areas of health, dentistry has been characterized by a practice with little focus on prevention of diseases and the preventive actions, when employed, often occur late, when the primary dentition is already largely compromised by tooth decay.The results achieved by Dentistry for Babies, in various parts of the world, have pointed to a promising future. That emphasize the particularities of children's growth and development and considered the baby as a whole, and not only by the point of view oral health.
\end{abstract}

Conclusion: The practice of dentistry for babies allows the possibility to promote health and prevent disease, in a highly simple, effective and low cost manner.

Key-words: Health promotion, preventive dentistry, dentistry for babies, oral health education

\section{Introducción}

La odontología general se caracteriza por ser una profesión que no impulsaba hábitos preventivos de enfermedades bucales, principalmente en niños. Hoy en día, es recomendable realizar la primera consulta odontológica durante el primer año de vida del infante para garantizar el acercamiento a la familia, educar sobre promoción y mantenimiento de la salud oral y evitar las consultas de urgencia en etapas más avanzadas de la enfermedad, cuando la dentición decidua ya ha sido altamente comprometida por la caries dental.

Antiguamente, se recomendaba retardar la atención odontopediátrica hasta cumplir los 6 años de edad, dejando en plano secundario la atención para la gestante y para el paciente infante (etapa entre los 0 a 3 años)., ${ }^{1,2}$ Esto ocurría por el mal establecimiento de prioridades, el aumento de la demanda de atención odontológica en la etapa escolar y la falta de recursos humanos y financieros en el ámbito de salud bucal. Actualmente, la influencia cultural de la población y de los profesionales de la salud bucal no contem 
pla la necesidad del tratamiento odontológico antes que la dentición decidua esté completada o hasta los tres años de edad, cuando el niño presenta las condiciones psicológicas que posibilitan la atención. Sin embargo, ante los nuevos conocimientos sobre psicología infantil y sobre la importancia del cuidado de los dientes deciduos en el arco dentario hasta su exfoliación, los conceptos sobre la atención odontopediátrica fueron evolucionando.

La odontología para bebés comprenden los cuidados que comienzan en los primeros meses de vida (0-36 meses) y que está siendo ampliamente difundida actualmente. Sin embargo, aún existe una alta prevalencia de enfermedades bucales, especialmente caries dental, que ocurre de forma agresiva y progresiva en los infantes. ${ }^{3}$

Se debe recalcar la importancia de que los profesionales de la salud, en la red de salud pública o privada, reconozcan que se debe comenzar la promoción y prevención de la salud bucal del infante, en la etapa más temprana de la vida, preferencialmente desde la etapa prenatal. El objetivo de este trabajo es presentar por medio de una revisión de la literatura, la filosofía de la Odontología para Bebés en la actualidad.

\section{Revisión de la Literatura}

\section{Inicio de la Atención Odontológica a niños.}

En los EUA, durante los años 1935 y 1945, se recomendaba que la primera visita al dentista del niño fuera a partir de los 12 años de edad, al completar la erupción de los dientes permanentes. Poco tiempo después, se comenzó a orientar a los padres a llevar a sus hijos a su primera consulta entre los 6 y 7 años. En los años 50, se estableció la edad de 3 años como la más ade- cuada para iniciar la evaluación de los infantes. ${ }^{1}$ La decisión estaba basada, principalmente, en la capacidad del niño de entender y cooperar en tratamientos odontológicos. ${ }^{2}$ Sabiendo que las enfermedades bucales no discriminan la edad del paciente, se debe anticipar la atención, a través de un protocolo no invasivo, que garantice una respuesta positiva frente al tratamiento ${ }^{4}$, aumentando la posibilidad de que tenga una buena salud bucal en el futuro. ${ }^{5}$

Actualmente, los conocimientos sobre el comportamiento y la fisiología de los infantes, nos conlleva a la necesidad de iniciar la atención odontológica de forma temprana. Según Walter y Nakama6 ${ }^{6}$ la edad ideal para la primera visita al dentista es a los 12 meses, pues mejora la posibilidad de mantener una buena salud bucal. Por otro lado, otros autores recomiendan que la primera consulta sea antes de los 12 meses de edad. ${ }^{7}$ La American Academy of Pediatric Dentistry (2014) recomendó que la implementación de los cuidados odontológicos en el infante inicie antes de la erupción el primer diente deciduo. ${ }^{8}$ A pesar de esto, se conoce que hoy en día, aún existen profesionales que continúan ejerciendo bajo la filosofía tradicional. Cotton y col. ${ }^{9}$ reportaron que aproximadamente $44 \%$ de los dentistas incluidos en su estudio, todavía creen que la primera consulta del infante debe ocurrir a los 3 años de edad.

\section{Tratamiento Preventivo.}

El tratamiento preventivo del infante se basa en el tratamiento integral en secuencia evolutiva y jerárquica, involucrando aspectos educativos, preventivos y curativos. Inicialmente se promueve la eliminación de factores de riesgo, mejorar la resistencia del huésped, de los dien 
tes y finalmente tratar y controlar los problemas existentes. La fase educativa se desenvuelve mediante acciones colectivas o individuales, según sea el caso, en dos etapas. En la primera etapa, direccionada a los padres, se busca remarcar de manera general la importancia del tratamiento odontológico enfocándonos en el cómo y el porqué; centrándonos en temas como: la primera consulta, lactancia natural y/o artificial adecuada, evitar hábitos de succión no nutritivos por tiempo prolongado, controlar el amamantamiento nocturno a través de consejerías dietéticas, entender sobre la transmisibilidad de la caries dental y la importancia de realizar la higiene bucal del infante. La segunda etapa de la fase educativa, direccionada a los padres mediante el ejemplo en el niño, se definirá los factores de riesgo y se establecerán maneras de controlar y/o eliminarlos, enseñando cómo implementar cada medida. ${ }^{6}$

Según la filosofía utilizada en la Clínica de Bebé de la Universidad Estadual de Londrina (UEL-SP), la determinación del riesgo de caries es realizada por el método anamnésico-clínico empleando indicadores ambientales como: higiene bucal/cepillado, consumo de azúcar, amamantamiento nocturno y posibilidad de la contaminación con bacterias cariogénicas. A partir de estos datos, se puede clasificar el riesgo del paciente como severo, alto, medio alto, medio y bajo. Los pacientes de bajo riesgo no poseen ningún factor desfavorable, mientras que los pacientes de riesgo severo tienen todos los factores desfavorables. El riesgo medio presenta un factor desfavorable, riesgo medio alto presenta dos factores desfavorables y el factor alto, tres factores negativos. ${ }^{6}$

Cunha y col. ${ }^{10}$ establecieron factores familiares y clínicos para determinar el riesgo de caries en infantes. Para estos autores, estos pacientes se pueden considerar de bajo riesgo cuando no tienen una dieta cariogénica, cuando sus padres tienen una actitud preventiva, tienen una higiene bucal correcta y regular y exposición a flúor. En contraste, los infantes serán clasificados en riesgo alto si tienen una dieta cariogénica, usan biberón durante la noche, tienen una higiene bucal deficiente o ausente, no tienen contacto con flúor y los padres no tienen conocimientos de la importancia de los cuidados preventivos en salud bucal.

Además de los cuidados preventivos y educativos, realizados por el profesional en la consulta y diariamente por los padres, los controles periódicos son necesarios para mantener la motivación, realizar los tratamientos preventivos y clínicos en el infante. Para la realización de cual

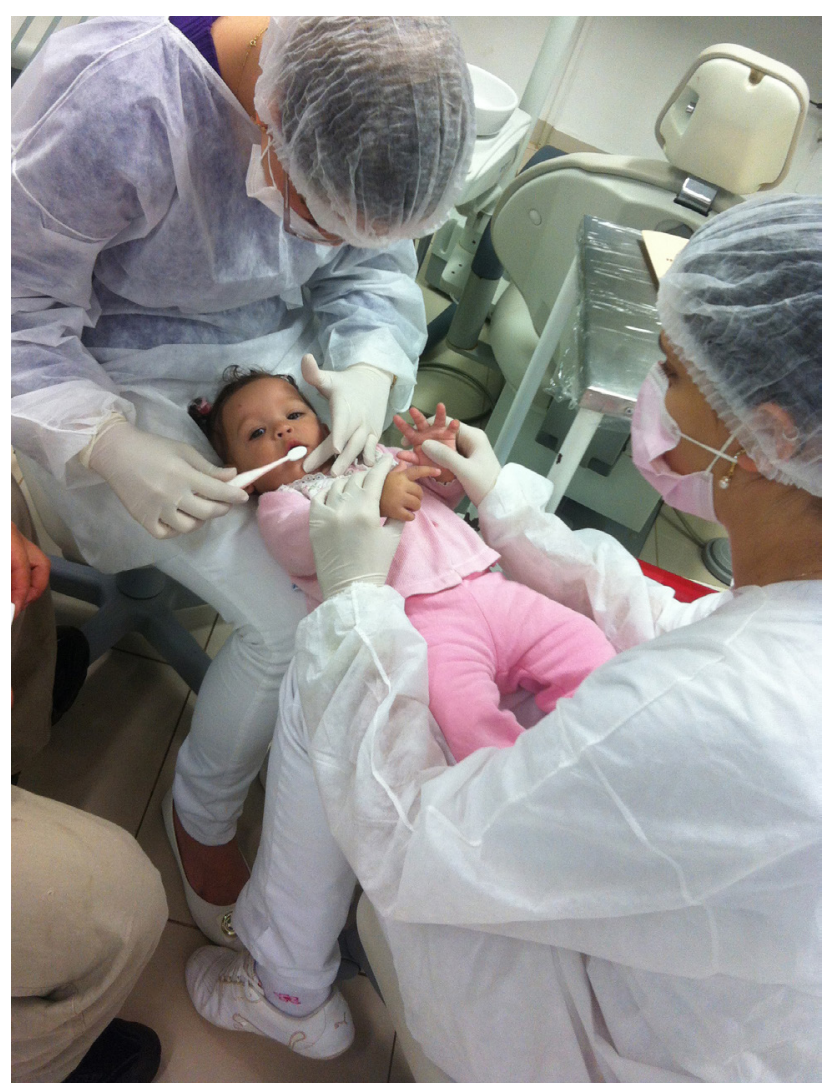

Figura 1. Técnica rodilla a rodilla para higiene bucal. 
quier procedimiento preventivo o restaurador, en el consultorio se puede realizar en el sillón dental, sosteniendo al bebé en las piernas de uno de los padres, colocándose en posición "rodilla a rodilla" con alguno de los padres (fig. 1); también se pueden usar sillas adaptadas especialmente diseñadas para infantes, o con ayuda de pequeñas camillas diseñadas para la inmovilización. Es de responsabilidad del profesional, la realización de exámenes y procedimientos agradables en ambientes tranquilos y confortables, buscando la comodidad del paciente en la clínica odontopediátrica. ${ }^{11}$

\section{Dieta}

Después que nace el bebé hasta los 6 meses, se le debe alimentar de manera exclusiva con leche materna. Después de los 6 meses continúa con lactancia materna y comienza la alimentación complementaria al introducir papillas, jugos en taza de entrenamiento, vasos especiales (fig. 2), sin la necesidad de usar biberón, ya que no se tiene la necesidad fisiológica de la succión. 12,13,14 La consistencia de los alimentos debe aumentar progresivamente para estimular la función masticatoria y estimular la erupción dentaria. La programación metabólica adecuada puede prevenir el desarrollo de obesidad y otras enfermedades asociadas a lo largo de la vida. ${ }^{13}$

La leche materna contiene un mayor porcentaje de lactosa que la leche bovina. Este hidrato de carbono, a pesar de tener un menor efecto cariogénico que la sacarosa, también puede promover desmineralización al encontrarse en contacto con el esmalte dental por un tiempo prolongado. La falta de conocimientos de los padres en cuanto a la necesidad de mantener una correcta higiene bucal de su hijo y sobre el potencial ca-

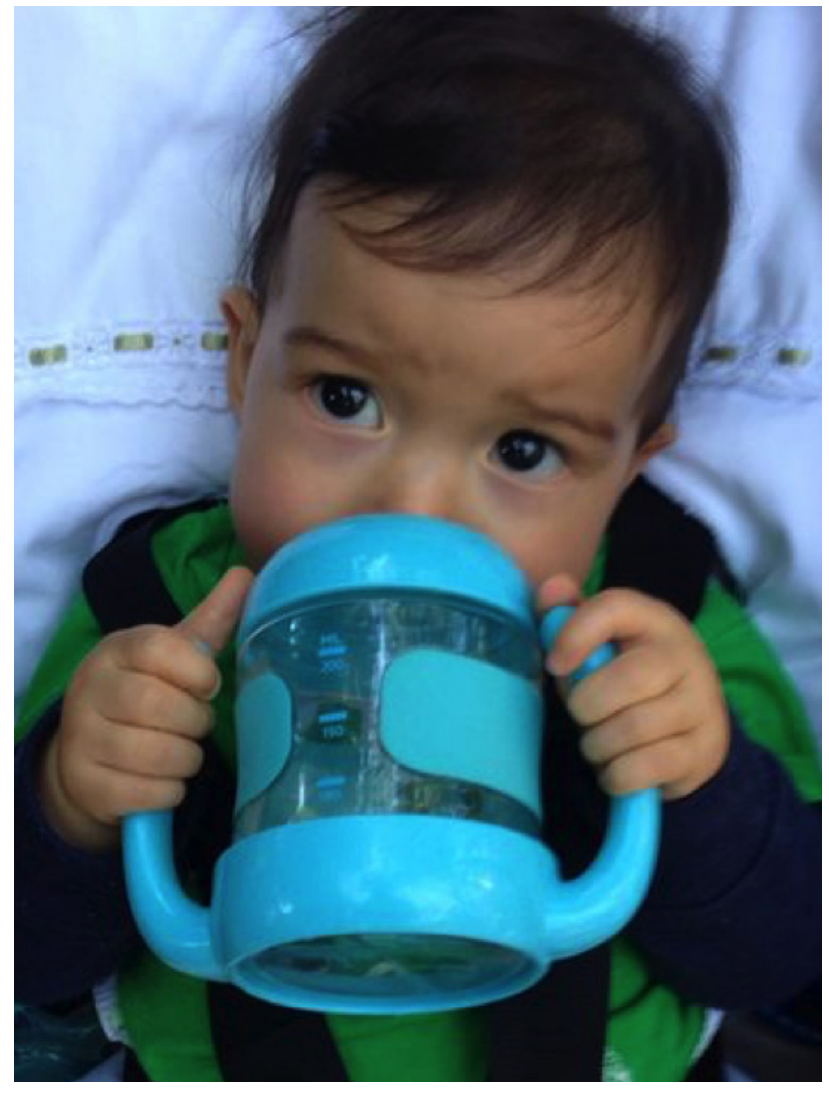

Figura 2. Uso de taza de entrenamiento.

riogénico de la leche materna puede conllevar a que los infantes desarrollen la enfermedad durante o después del amamantamiento. ${ }^{15}$ Durante el sueño, el flujo salival y los movimientos musculares de la lengua y los carrillos, responsables de la autolimpieza de la cavidad bucal, están disminuidos, por consecuencia, ocurre una adherencia de la leche al esmalte causando la caída del $\mathrm{pH}$ salival a niveles altamente ácidos, favoreciendo la adhesión bacteriana y la posterior colonización de microorganismos acidogénicos en la superficie del esmalte. ${ }^{15}$ Por lo tanto, la frecuencia y el tiempo de exposición a azúcares son factores importantes para determinar la posibilidad de desarrollar caries de infancia temprana.

Se debe controlar la ingesta de azúcares mediante medidas educativas para lograr la reducción y no su total eliminación de la dieta. Esto signi 
fica que se debe concientizar a los padres para lograr la reducción voluntaria de la frecuencia y la cantidad de estos alimentos. Se sabe que, en cuanto a mayor la frecuencia de ingesta, mayor el número de caídas del $\mathrm{pH}$, de modo que se favorece el desarrollo de caries dental. Por estas razones, se debe recalcar el efecto del azúcar en la caries dental y su importancia de limitar el consumo, además de garantizar la inclusión de la higiene bucal después de su consumo.

\section{Transmisibilidad de la Caries Dental}

En la vida intrauterina, el feto se encuentra en un ambiente aséptico, incluyendo la cavidad bucal. Se presume que durante el parto, o unas horas después, la cavidad bucal es colonizada por microorganismos provenientes del tracto genital, de la madre, cuidador o del mismo medio ambiente. $^{16}$

Existe una amplia gama de especies que habitan la cavidad bucal del infante durante el primer año de vida, como Streptococcus, Staphylococcus, Neisseria, Candida, Lactobacillus, coliformes e Veillonella. ${ }^{16}$ Los estreptococos del grupo mutans, agentes principales en el desarrollo de la caries dental colonizan a partir del nacimiento, sin embargo, de manera altamente significativa, sólo después de la erupción dentaria, cuando se provee una superficie para la adherencia microbiana. ${ }^{17}$ La aparición de microorganismos anaerobios estrictos también se relaciona directamente a la erupción dental. Según la literatura, la fuente principal de infección por Streptococcus mutans en la cavidad bucal del infante es la madre. ${ }^{18}$ Sin embargo, la transmisión de microorganismos no está limitada a la interacción madre/ hijo, sino que se extiende entre las personas con las que el infante convive. ${ }^{19}$
La transmisión de microorganismos cariogénicos ocurre por medio de contactos directos o indirectos. El contacto directo vía saliva, ocurre principalmente cuando las cargas de $S$. mutans en la saliva materna son elevadas. Varios hábitos de la madre pueden promover la transmisión de bacterias: hablar cerca del niño, probar alimentos con el mismo cubierto, limpiar el chupón o pacificador con la boca o como besar al infante en la boca. El contacto indirecto ocurre por vía de objetos tales como: utensilios, cucharas, tazas, juguetes, cepillos dentales contaminados por bacterias cariogénicas ${ }^{20} \mathrm{o}$ pacificadores. ${ }^{21,22}$ Además, el grado de transmisión va a depender de diferentes factores como: el grado de infección de los padres, cuidadores o compañeros, la frecuencia de contacto con el niño, la dieta y el estado inmune del infante.

Una alternativa lógica para el control de la caries dental es prevenir o retardar la infección lo máximo posible, ya que ha sido demostrado que si la infección es demorada, menor será el desarrollo de caries. La "ventana de infectividad", tiempo durante el cual el niño está más susceptible a la colonización bacteriana, varía de los 19 a 31 meses de edad con promedio de 26 meses. ${ }^{18}$ Se debe recalcar que la transmisibilidad no está limitada a esta "ventana", ya que se han estudiado poblaciones en las cuales las madres tienen cepas de estreptococos del grupo mutans más heterogéneas que los hijos, demostrando así que las cepas adicionales pueden ser adquiridas con el crecimiento del niño.

La aplicación de un programa profiláctico básico en madres con altas concentraciones de S. mutans en la saliva puede reducir el riesgo de transmisibilidad. El programa debe incluir la orientación y la motivación para reducir el ries 
go de caries del infante, uso de clorhexidina y correctos hábitos alimentarios. Por medio de la aplicación de estas medidas se podrá prevenir o retardar la infección cariogénica en los infantes.

\section{Higiene Bucal}

La higiene bucal envuelve un conjunto de medidas que tienen como objetivos la remoción de biofilm dental y la prevención de su reincidencia, pudiendo ser realizadas a través de medios mecánicos y químicos. Los padres juegan un papel importante en el inicio de la vida de los hijos, ya que tienen la posibilidad de introducir los hábitos de higiene diaria en una etapa temprana, ${ }^{17}$ incluso antes de la erupción dental, a través de masajes gingivales y limpieza para establecer una microbiota bucal saludable. ${ }^{18}$ La remoción manual de los restos de alimentos acumulados en las comisuras labiales y en la cavidad bucal puede ser realizada mediante el uso de dedales especiales, gasas suaves o paños limpios envueltos en el dedo índice preferiblemente de noche después de la última alimentación y solamente una vez al día, ya que las inmunoglobulinas que contiene la leche materna protegen a la mucosa bucal contra las infecciones. La higiene bucal puede ser realizada antes de dormir, generalmente durante o después del baño para que el niño la asocie a la higiene corporal durante toda la vida. (fig. 3)

Se recomienda que los infantes que aún no tienen dientes o que sólo presentan dientes anteriores, sea realizada la higiene bucal con gasas o paños humedecidos en diversas soluciones. La indicación de estas soluciones es hecha por diferentes profesionales que no conocen los efectos e impactos que pueden tener al tener contacto con la microbiota bucal del infante.

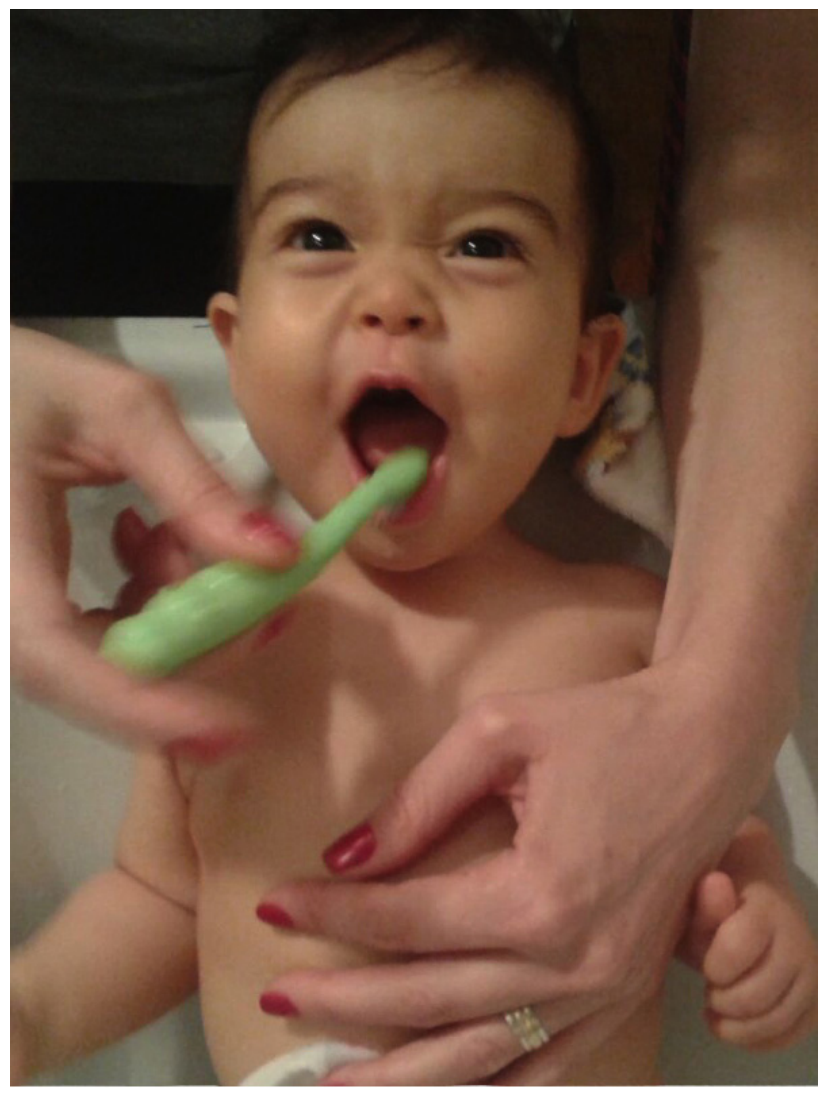

Figura 3. Higiene bucal asociada a la higiene corporal.

Modesto y $\mathrm{col}^{20}$ enviaron un cuestionario a pediatras y odontopediatras de diferentes ciudades brasileras y verificaron que las soluciones de limpieza más recomendadas fueron el bicarbonato de sodio al $10 \%$, peróxido de hidrógeno (H2O2) al 3\% y diluido de $1 / 4$ a 1/16, solución de manzanilla (preparado con $1 \mathrm{~g}$ de planta seca en $250 \mathrm{ml}$ de agua) y fluoruro de sodio $(\mathrm{NaF})$ al $0.02 \%$. A partir de estos datos, se evaluaron los impactos de estas soluciones en el biofilm dental y saliva de bebés in vitro. Los resultados demostraron que las soluciones de bicarbonato de sodio y la manzanilla no tenían actividad antimicrobiana, a diferencia de la solución con fluoruro de sodio (concentrado y diluido de $1 / 4$ a 1/16) y la solución de peróxido de hidrógeno (concentrado y diluido al 1/2) que sí presentaron actividad antimicrobiana sobre el biofilm dental. 
El peróxido de hidrógeno es recomendado sin que existan bases científicas o clínicas de su seguridad como agente en la higiene bucal. Su uso es controversial por su sabor desagradable, acción efervescente y ser potencialmente tóxico por causar peroxidación de lípidos en la membrana celular, además de potencial cancerígeno y carcinogénico, cuando se usa diariamente. En caso de su uso en infantes, puede alterar la microbiota bucal normal, ocasionando infecciones bucales crónicas, por el crecimiento de microorganismos oportunistas de la cavidad bucal como la Candida albicans. La microbiota bucal es una de las primeras barreras de defensa además de los factores específicos e innatos presentes en la saliva y fluidos gingivales y ha sido ampliamente investigada su importancia y necesidad en la cavidad bucal de los bebés.

Los iones flúor interfieren en la adhesión inicial de las bacterias, afectan el metabolismo bacteriano, es un agente cariostático y, en bajas concentraciones, inhibe la producción bacteriana de ácidos. En este estudio, se encontró que el fluoruro de sodio tiene efecto antimicrobiano, menor que el peróxido de hidrógeno, lo cual permite su uso racional en niños con alto riesgo a caries, es decir, presentan uno o más factores de riesgo, como la higiene bucal deficiente, ausencia de flúor tópico o sistémico, uso de biberón nocturno, el alto consumo de alimentos cariogénicos (más de 5 veces al día) o presencia de caries activa. En niños que no pertenecen al grupo de riesgo ( $\sin$ factores de riesgo) se recomienda el empleo de agua filtrada, solución salina o solución de manzanilla, que de acuerdo al estudio, no tienen efecto antimicrobiano.

En conclusión, para realizar la higiene bucal del infante se puede utilizar pañitos o gasas embebidas en agua filtrada, manzanilla o solución sali- na más no se recomienda el uso no supervisado del fluoruro de sodio ni la utilización del peróxido de hidrógeno, pues altera la microbiota normal de la boca. ${ }^{20}$

La utilización de otros agentes químicos antimicrobianos, como auxiliares al control mecánico del biofilm dental vienen siendo estudiados. En este contexto, la clorhexidina destaca por sus propiedades benéficas y altamente difundidas, indicada comúnmente en el tratamiento de pacientes con alto riesgo a caries dental, en pacientes especiales y después de cirugías o radioterapias.

El uso del cepillo dental se puede iniciar en el momento en el que erupciona el primer diente deciduo. (Fig. 4) El objetivo inicial del cepillado es establecer buen patrón de higiene bucal, fortaleciendo la remoción mecánica de biofilm dental de zonas accesibles. Los fabricantes de pastas dentales ofrecen una amplia gama de opciones, algunas con el objetivo específico de estimular la práctica del cepillado de los niños. Con relación a las orientaciones de los profesionales en higiene bucal en infantes, existe una interrogante latente en cuanto a cual pasta dental debe ser indicado como apoyo a los métodos mecánicos de limpieza.

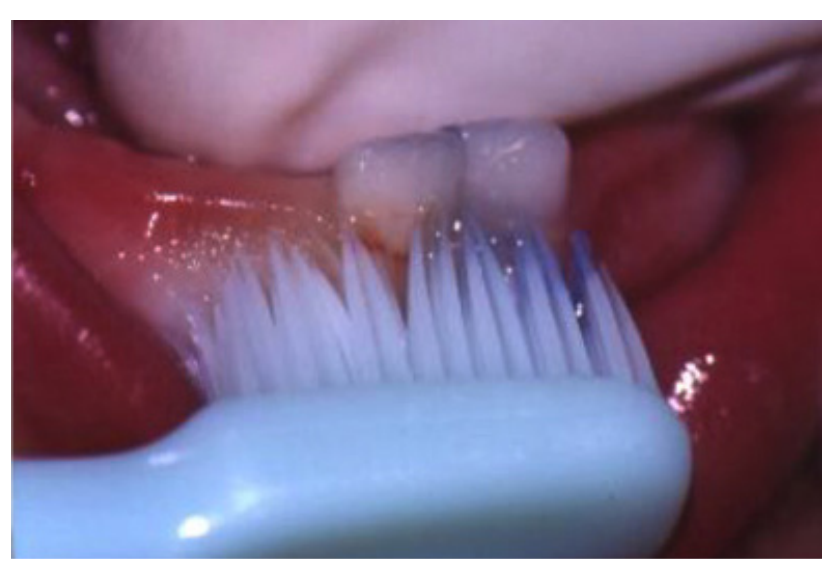

Figura 4. Cepillado de los primeros dientes deciduos. 
Se sabe que los infantes menores de 3 años, ingieren cerca de $30 \%$ de la pasta dental durante cada cepillado, debido a la inhabilidad de escupir. Es por esto, buscando reducir el riesgo de fluorosis dental, surgieron pastas dentales sin flúor y con un nivel de flúor reducido (500ppm). Sin embargo, estudios demostraron que las pastas con una menor cantidad de flúor en su composición no tienen la efectividad que poseen las pastas convencionales (1000ppm) y que no existen evidencias científicas para seguir incentivando su uso en la prevención de la caries y la fluorosis. ${ }^{17,23,24,25}$

Actualmente, es ideal indicar el uso de dentífrico convencional usado por el adulto, controlando la cantidad aplicada de acuerdo con la edad, sin tomar en cuenta la cantidad de flúor que posee. Hoy se sabe que la dosis segura diaria de flúor es de $0.05 \mathrm{mg}$ por $\mathrm{kg}$ de peso. ${ }^{26} \mathrm{Se}$ determinó que para los infantes menores de 3 años de edad se debe usar solo una "mancha" (smear - 0.1mg) o la cantidad de un grano de arroz (rice size $-0.1 \mathrm{mg}$ ), para los niños de 3 a 6 años de edad se recomienda la cantidad de una arveja (pea size $-0.25 \mathrm{mg}$ ) y luego de los 6 años se debe usar la técnica transversal $(0.36 \mathrm{mg})$ recomendada por la American Academy of Pediatric Dentistry (AAPD, 2014) ${ }^{8}$ y la American Dental Association (ADA, 2014) ${ }^{27}$ (fig. 5). Después de la información presentada verbalmente, es importante el uso de fotos y realizar una técnica demostrativa de la aplicación de la pasta dental en el cepillo dental para orientar a los padres.

Villena ${ }^{28}$ realizó un estudio con el objetivo de evaluar la influencia de diferentes técnicas de madres y niños al aplicar pasta en el cepillo dental. Entre estas, la llamada "técnica transversal" proporcionó menores cantidades de pasta dental. La técnica convencional "horizontal" pro-

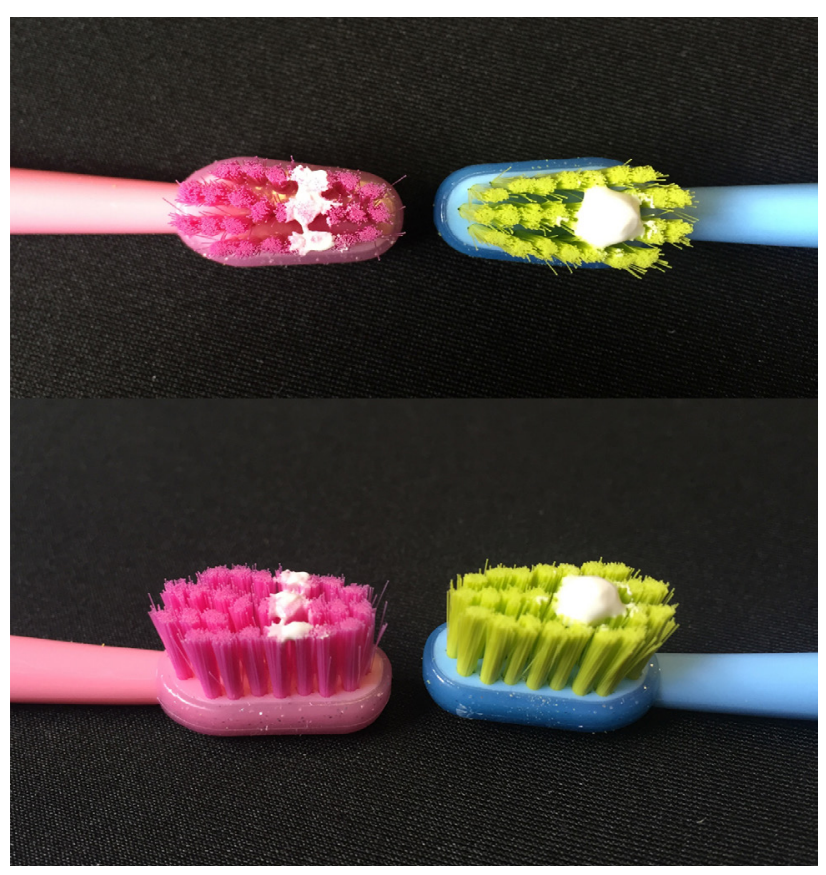

Figura 5. Comparación entre cantidades de pasta dental aplicada: "smear" (izquierda) y "pea-size" (derecha).

porcionó mayores cantidades de pasta mientras que la técnica 'pea size' proporcionó cantidad intermedias. En todas las técnicas evaluadas, las madres aplicaron mayores cantidades de pasta dental que los niños.

La orientación educacional es una importante alternativa para promover el uso adecuado de las pastas dentales. La educación debe ser direccionada a los padres y envolver aspectos relacionados a la supervisión del cepillado de sus hijos, evitando que ingieran pastas por su apariencia y sabor agradable, no dejándolo al alcance de los niños y reduciendo la cantidad usada en el cepillo dental. La prevención de ingesta de grandes cantidades de pasta dental continúa siendo un problema importante que no solo pueden ser reconocidos por profesionales, mas también por organizaciones de la salud y fabricantes de los productos, que insisten en promover comerciales con el slogan "sabor que los niños adoran" e incentivan el empleo de cantidades exageradas en el cepillo dental. 


\section{Conclusiones}

El tratamiento odontológico del infante brinda la posibilidad de mantener la salud, prevenir la enfermedad y representa una buena práctica de promoción de la salud, de una manera muy simple, eficaz y a bajo costo, el cual es posible integrarlo a cualquier sistema de salud. El odontopediatra es el responsable de educar para la salud a la gestante, a los padres, cuidadores y representantes en cuanto a hábitos dietéticos, de higiene bucal, transmisibilidad de la caries y el uso racional de fluoruros.

\section{Referencias bibliográficas}

1. Torriani DD. Análise do comportamento de bebês durante o atendimento odontológico: relação entre sexo, idade e dentes irrompidos [tese de mestrado]. Araçatuba (SP): Universidade Estadual Paulista Julio de Mesquita Filho; 1999. 2. Mussen PH, Conger JJ, Kagan J. Child development and personality. 6a ed. New York. Harper \& Row; 1984.

3. Magalhães AC, Rios D, Honório HM, et al. Estratégias educativas-preventivas para a promoção de saúde bucal na primeira infância. Odontologia. Clín. -Científ. 2009; 8(3):245-249.

4. Bonecker MJ. Abordagem odontopediátrica integral em clínica de bebês. Rev Ass Paul Cirurg Dent 1995; 49(4): 307-10.

5. Almeida ER, Guedes-Pinto AC. Hábitos alimentares. In: Guedes-pinto AC. Odontopediatria clínica. São Paulo: Artes Médicas. p. 73-86, 1998.

6. Walter LRF, Nakama R. Prevenção da cárie dentária através da identificação, determinação e controle dos fatores de risco em bebês- Parte I. J Bras Odontoped Odonto Bebê 1998; 1(3): 91-100.

7. Novak A, Crall J. Prevenção da doença dental. In: Pinkhan JR. Odontopediatria: da infância à adolescência. $2^{\underline{a}}$ ed. São Paulo: Artes Médicas; p. 214-31; 1996.

8. American academy of pediatric dentistry. Guideline on fluoride therapy. Reference manual 2014-15. Pediatr Dent 2014; 34(6): 171-4.

9. Cotton KT, Seale NS, Kanellis MJ, Damiano PC, Bidaut-Russell M, McWhorter AG. Are general dentists' practice patterns and attitudes about treating Medicaid - enrolled preschool age children related to dental school training? Pediatr Dent 2001; 23(1): 51-5.

10. Cunha RF, Delbem ACB, Percinoto C, Saito TE. Dentistry for babies: a preventive protocol. J Dent Child 2000; $53: 89-92$.

11. Corrêa MSNP. Odontopediatria na primeira infância. São Paulo: Santos; 1998.

12. Ollila P, Niemela M, Uhari M, Larmas M. Prolonged pacifier-sucking and use of a nursing bottle at night: possible risk factors for dental caries in children. Acta Odontol Scan 1998; 56: 233-7.

13. Romulus-Nieuwelink JJ, Doak C, Albernaz E, Victora CG, Haisma H. Breast milk and complementary food intake in Brazilian infants according to socio-economic position. Int J Pediatr Obes 2011; 6(2): 508-14.

14. Camargo MCF. Programa preventivo de maloclusões em bebês. 1st ed. In: Gonçalves ENA, Feller C. Atualização na clínica Odontológica: a prática da clínica geral. São Paulo: Artes Médicas, 1998. p.405-42

15. Erickson PR, Mazhari E. Investigation of the role of human breast milk in caries development. Pediatr Dent $1999 ; 21$ (2): 86-90.

16. MacFarlane TW, Saramanayake LP: Oral ecossystem and dental plaque. In Oral Microbiology. London: Wright 1989, p 21-3 
17. American academy of pediatric dentistry. Guideline on infant oral health care. Reference manual $2014-2015$. Pediatr Dent 2014; 37 (6): 146-150

18. Caufield PW, Li Y. The fidelity of initial acquisition of mutans streptococci by infants from their mothers. J Dent Res 1995; 74(2):681-85.

19. Azevedo RVP. O emprego da bacteriocinotipagem (mutacinotipagem), no rastreamento epidemiológico de estreptococos do grupo mutans [tese de doutorado]. São Paulo (SP): Universidade de São Paulo; 1988.

20. Modesto A, Lima KC, Uzeda M. Effects of solutions used in infant's oral hygiene on biofilms and oral microorganisms. ASDC J Dent Child 2000; 67(5): 338-44.

21. Comina E, Marion K, Renaud FN, Dore J, Bergeron E, Freney J. Pacifiers: a microbial reservoir. Nurs Health Sci 2006; 8(4): 216-23.

22. Nelson-Filho P, Silva LA, Silva RA, da Silva LL, Ferreira PD, Ito IY. Efficacy of microwaves and chlorhexidine on the disinfection of pacifiers and toothbrushes: an in vitro study. Pediatr Dent 2011; 33(1): 10-3.

23. Ammari AB, Bloch-Zupan A, Ashley PF. Systematic review of studies comparing the anti-caries efficacy of children's toothpaste containing 600 ppm of fluoride or less with high fluoride toothpastes of 1,000 ppm or above. Caries Res 2003; 37(2): 85-92.

24. Dos Santos AP, Nadanovsky P, de Oliveira BH. A systematic review and meta-analysis of the effects of fluoride toothpastes on the prevention of dental caries in the primary dentition of preschool children. Community Dent Oral Epidemiol 2013; 41(1): 1-12.

25. Santos AP, Oliveira BH, Nadanovsky P. Effects of low and standard fluoride toothpastes on caries and fluorosis: systematic review and meta-analysis. Caries Res 2013; 47(5): 382-90.

26. Young V, Garza C. Dietary Reference Intakes for Calcium, Phosphorus, Magnesium, Vitamin D and Fluoride. Standing Committee on the Scientific Evaluation of Dietary Reference Intakes, Food and Nutritional Board, Institute of Medicine. Food and Nutrition Board, Institute of Medicine. National Academy Press: Washington, DC, 1997.

27. American Dental Association Council on Scientific Affairs. Fluoride toothpaste use for young children. J Am Dent Assoc 2014; 145(2): 190-1.

28. Villena RS. An investigation of the transverse technique of dentifrice application to reduce the amount of fluoride dentifrice for young children. Pediatr Dent 2000; 22(4): 312-7.

Recibido 3/12/2016

Aceptado 10/05/2017

Correspondencia: Marina Moscardini Vilela, Av. do Café, S/N CEP 14049-900, Ribeirão Preto, São Paulo, Brasil. Fax 163315 3995. Email: marina.vilela@usp.br 